DISTRIBUTION STATEMENT A. Approved for public release; distribution is unlimited.

\title{
Passive Autonomous Acoustic Monitoring of Marine Mammals: System Development Using Seaglider ${ }^{\mathrm{TM}}$
}

\author{
Final Report \\ 30 January 2015 \\ Neil M. Bogue \\ Applied Physics Laboratory \\ University of Washington \\ Box 355640 \\ Seattle WA 98195-5640 \\ phone: (206) 221-7687 fax: (206) 543-6785 email: bogue@apl.washington.edu
}

Award Number: N00014-10-1-0515

\section{LONG-TERM GOALS}

A research group within the Applied Physics Laboratory of the University of Washington (APL-UW) is dedicated to the use of autonomous underwater vehicles in support of U. S. Navy (hereafter Navy) missions. The group generally uses the Seaglider, developed at APL-UW, and invents or adapts instruments and glider behavior to support specific Navy mission requirements. This group is informally called the Applied Seaglider Group, whose acronym (ASG) is also used to describe the specially modified Seagliders themselves.

This effort described in this report was ASG's second award as part of the Office of Naval Research's (ONR) Passive Autonomous Acoustic Monitoring (PAAM) program. The initial long-term goals of the PAAM program, as outlined by the original ONR program managers, Drs. Terri Paluszkiewicz and Doug Marble, were to create the following capabilities.

- Perform persistent and autonomous passive acoustic monitoring of a 500-1000 square nautical mile Navy exercise area for presence of marine mammals.

- Monitor for three weeks prior to, three weeks during, and three weeks after a typical exercise.

- Detect, classify and localize (DCL) vocalizing marine mammals.

- Provide actionable information in a timely manner to the officer in tactical command to support marine mammal mitigation efforts.

These goals changed over the life of the program, primarily due to external factors. First, as outlined above, we concentrated our efforts on a specific near real-time DCL mission, with an emphasis on mitigation of adverse effects of Navy active sonar on beaked whales. Then, the focus became broadband high-fidelity recordings for marine mammal surveys. Thus, the primary long-term goal of the ONR PAAM program became to provide a persistent (several months) autonomous marine 
mammal monitoring capability in Navy operating areas that are remote or difficult to monitor by ships or aircraft. These include parts or all of the Pacific Northwest, Hawai'i Range Complex, Gulf of Alaska, and Mariana Islands operating and training areas.

The long-term goals of the particular award covered by this final report were (1) to improve and extend the capabilities of the baseline Seaglider PAAM system, with (at the end of the program) particular attention to the long-duration marine mammal survey mission, and (2) to provide a path to transition so that the Seaglider PAAM system could be made available to others in the marine mammal monitoring community.

\section{OBJECTIVES}

With previous ONR funding (N00014-08-1-0309), we replaced the original passive acoustic detection, recording, and on-board processing capabilities of the Applied Seaglider (ASG), with particular attention to the automated detection of beaked whale echolocation clicks. In particular, we designed and built a new passive acoustic detection and recording system for ASG, and tested this system in the field several times.

The objectives of this program changed as the long-term goals changed (described above). The objectives were originally as follows.

- Enhance detection, classification, and localization performance with multiple hydrophones or small hydrophone arrays

- Improve the automated detection and classification (software) components

- Successfully demonstrate the system in a Navy fleet exercise

- Successfully demonstrate the single-channel acoustic recording system in a long-duration mission in a relevant Navy operating area.

In the last year of the program, based on consultations with our ONR program manager, Dr. Mike Weise, and our colleagues Drs. Mellinger and Klinck at Oregon State University, the primary objective became to make the Seaglider/PAAM single-channel acoustic recording system as reliable and useful as possible for the U.S. Navy Facilities Engineering Command (NAVFAC, responsible for management of Navy operating areas), in support of their regulatory and permitting requirements. This lowered the priority of the DCL mission, which relied on on-board software performing near realtime detection and classification, and multiple hydrophones for better localization.

\section{APPROACH}

Our approach was as follows.

- Treat the single-hydrophone PAAM electronics system as deployed at AUTEC in June, 2010, and at SCORE in January, 2011, as a baseline.

- Collaborate with Drs. David Mellinger and Holger Klinck at Oregon State University (OSU) on improved beaked whale detection and classification algorithms. 
- Test installation of a second omnidirectional hydrophone to minimize signal obstruction by the Seaglider pressure hull and enable primitive localization of marine mammal vocalizations.

- Collaborate with Ocean Acoustical Services and Instrumentation Systems (OASIS), Inc., of Lexington MA, on the integration of an L3 Chesapeake Sciences Mills-cross high-frequency array.

The final design of the L3 Chesapeake Sciences Mills-cross high-frequency array proved to be larger (in mass, volume, and dimensions) than the Seaglider could carry without a substantial redesign of the Seaglider itself. In consultation with Dr. Weise at ONR and P. Abbott of OASIS, this aspect of the program at APL-UW was terminated. In place of the OASIS collaboration, the following approach was taken.

- Design and build a new revision (Rev. B) of the PAAM electronics board, with microSD card storage to replace the original USB-based storage design and an additional CPLD to free cycles on the main processor for DCL computations.

- Enable multiple active channels on the PAAM electronics board.

- Execute long-duration (greater than one month) missions.

- Continue to work closely with Drs. Mellinger and Klinck at Oregon State University for scientific guidance and analysis.

Over the course of the program, key participants at APL-UW, in addition to the Principal Investigator, were Jim Luby (co-PI and electrical engineer), Bill Jump (hardware and system design engineer), Sean Lastuka (electrical engineer), Sean McPeak (electrical engineer), Geoff Shilling (software engineer), Trina Litchendorf (ASG Lab), Angie Wood (ASG Lab), and Paul St. Laurent (ASG Lab). Drs. David Mellinger and Holger Klinck at OSU provided detection and classification algorithms, data analysis, and expert scientific consultation. Phil Abbot, Chuck Gedney, and Dave Morton at OASIS, Inc., collaborated on the Mills cross hydrophone array, which was fabricated by L3 Chesapeake Sciences Corporation.

\section{WORK COMPLETED}

The legal framework was established between APL-UW, OASIS Inc., L3 Chesapeake Sciences, and iRobot (the commercial license holder for Seaglider at the time) to allow for exchange of technical information relating to the integration of a small (hocky puck-sized) Mills cross format $5 x 5$ highfrequency hydrophone array. As noted above, when the L3 Chesapeake Sciences sensor was completed, it proved to be too large to carry on the Seaglider without a substantial redesign of the Seaglider itself. We jointly agreed with ONR and OASIS to stop further efforts on this integration. OASIS, Inc. successfully pursued integration of the same sensor on a Slocum glider from Teledyne Webb Research, work that has been reported separately.

Hardware and software modifications were made to incorporate additional omnidirectional hydrophones on the standard Seaglider PAAM configuration. We installed HTI-99-HF omnidirectional hydrophones at the tip of each wing of a Seaglider, as shown in Figures 1 and 2. The hydrophone cables were routed and lashed along the trailing edge of the wings. 
Flight tests were performed using Seaglider S/N 178 (sg178) equipped with wingtip-mounted HTI99HF hydrophones. The tests were done to verify the ability of Seaglider to achieve stable flight, with adequate speed through the water, in the presence of the additional drag caused by the wingtipmounted hydrophones. A basic flight characteristic plot in this configuration is shown in Figure 3. No acoustic sampling was done during this flight test.

A second revision (Rev. B) of the PAAM electronics board was designed, laid-out, and manufactured. This revision of the PAAM board contains a number of improvements, including more CPLD capacity and a microSD card based data handling system. The additional CPLD capacity will offload the main PAAM system ARM-9 processor from tasks associated with management of the digitization, buffering, and distribution of the acoustic data stream. This will leave more cycles available on the ARM-9 for the on-the-fly detectors and the subsequent execution of classifier code. The microSC card system will provide eight microSD card receptacles solely for data storage, and one for system and working space. The current maximum capacity of high-quality and high-reliability microSD cards is $128 \mathrm{~Gb}$, so this system will provide about $1 \mathrm{~Tb}$ of storage. The system's initial operating capability configuration used $64 \mathrm{~Gb}$ microSD cards, for about $0.5 \mathrm{~Tb}$ of storage.

One significant deployment was completed under this award, using the original (Rev. A) PAAM board. Seagliders sg178 and sg179 were launched on 11JUN2012 approximately 30 nautical miles due west of Westport WA. The plan was to run sg178 in offshore-onshore transects with one end at J. Hildebrand's HARP mooring at approximately $47^{\circ} 30^{\prime} \mathrm{N}, 125^{\circ} 21^{\prime} \mathrm{W}$. Seaglider sg179 was to survey along the Washington coast just offshore of the $1000 \mathrm{~m}$ isobath, with significant time spent surveying atop the HARP mooring mentioned above.

Seagliders S/N 178 and 179 were recovered on 12JUL2012, about 25 nautical miles due west of Westport WA, after completing 149 and 155 dives, respectively. Surfacing positions for each Seaglider are shown in Figure 4.

\section{RESULTS}

The flight tests on Seaglider S/N 178 (sg178) carrying HTI-99-HF hydrophones mounted on each wingtip were completely successful. Several dives were made in the vicinity of Shilshole Bay, Puget Sound WA on 26APR2011.

The basic dive performance plot for one of the dives is shown in Figure 3. The dive profile was normal, although sg178 was ballasted light for the operation, which resulted in slower descents and faster ascents than is typical. The Seaglider's specified vertical speeds were obtained with vehicle pitch angles well within normal ranges. Sufficient speed through the water was available to maintain heading control (course) and make progress over the ground against typical depth-averaged currents. All other Seaglider diagnostics shown in Figure 3 are within normal operating limits.

This positive result means that a Seaglider carrying wingtip-mounted hydrophones will be capable of normal dive profiles. The drag penalty, which will translate into an endurance penalty, is small enough that an open-ocean mission with many $1000 \mathrm{~m}$ dives will be required for a robust assessment.

The final revision to the PAAM electronics board is complete. Boards have been built and populated with electronics to the new design. These boards passed receiving inspection and were accepted. 
Results from our only field test in 2012 were somewhat disappointing. Seagliders sg178 and sg179 experienced significant problems with their PAAM systems during the mission, which resulted in their recovery after only one month of operations. Both Seagliders worked well as underwater vehicles. They were able to navigate successfully on their prescribed tracks. The vehicles themselves did not experience any problems.

Unfortunately, the data return was meager, as shown in Table 1.

\begin{tabular}{|c|c|c|c|c|}
\hline Seaglider & Dives & PAAM On & Data Recorded & Comment \\
\hline 178 & 149 & 17 & 13 & Noise \\
\hline 179 & 155 & 92 & 61 & Data management problems \\
\hline
\end{tabular}

Table 1. Summary of Seaglider/PAAM system performance on Washington coast mission, June-July 2012.

Seaglider 178 developed a noise contamination issue starting at about 55m depth on its second dive. After several days of unsuccessful attempts to remotely debug and solve this problem, the PAAM system on sg178 was secured for the duration of the mission. We believe this noise contamination was due to a small seawater leak into one of the underwater connectors between the hydrophone and the aft endcap of sg178's pressure hull. The leak may have been at the one of the connectors or somewhere along the cable between the hydrophone and the pressure hull. We have not seen this before on the PAAM system, but have had at least one similar failure of a Seaglider GPS/Iridium antenna cable on another project. Seaglider 178 passed all its pre-launch self-tests, and did a successful initial trim dive to $45 \mathrm{~m}$. The failure at $55 \mathrm{~m}$ on the second dive is suggestive of a pressure-induced leak of seawater into a connector (or wicking of water to the connector through a leak in the cable). We do not think this is a systematic problem. We will replace the hydrophone assembly, along with its cables and connectors, and repeatedly pressure cycle them before sg178's next mission.

When Drs. Mellinger and Klinck at OSU received the data after recovery of the Seagliders, they were able to successfully filter the noise from the acoustic time series of sg178. This rendered the data usable for beaked whale detection; the noise was out of the band of the beaked whale echolocation clicks. This is another lesson learned from this deployment: do not secure the acoustic system even if it appears that the data is noisy. Post-processing may be able to overcome the noise contamination of the signal. Note that the results of Drs. Mellinger and Klink's analysis of the recorded acoustic time series from this deployment of sg178 and sg179 has been reported elsewhere.

Seaglider 179 experienced problems with its data management system. The PAAM electronics are controlled by a single-board ARM-9 computer running Linux. The PAAM system configuration was to run with one microSD card as the system disk, and another microSD card as the primary data disk. Two USB sticks were cabled to the computer, under system software control with respect to mounting. Our approach was to record acoustic time series initially to the primary data disk, and as time and computing cycles allowed, move the time series data to one of the USB sticks. This would free storage space on the primary data disk as the mission proceeded.

About one week into the mission, the system began to have trouble mounting the USB sticks. It often became stuck in a cycle of repeatedly trying to check the integrity of the file system on the USB stick. 
That operation would often take longer than the time alloted to the movement of data. This effectively blocked use of that USB stick until the pilot held the Seaglider at the surface and manually managed the process. There were dives where the PAAM system was powered on, but spent its entire time trying to check the integrity of its various file systems, and was unable to record any data. Eventually, the problem effectively disabled the PAAM system on sg179. We did obtain 61 dives worth of good quality recordings. Those recordings were analyzed by the Oregon State University team led by Drs. Dave Mellinger and Holger Klinck, and results were reported elsewhere.

This type of behavior with the USB sticks is one reason the Rev. B PAAM board uses a bank of microSD cards. They have proven to be more reliable, and will not require successive mounts and unmounts. One microSD card will be mounted, written directly until full, then unmounted for the remainder of the mission. The next microSD card will be mounted in its place, and written until it, too, is full. This sequence will repeat until the storage capacity is exhausted, with one one mount and one unmount operation per microSD card. Note that it is the ever-increasing capacity of the microSD card technology that enables such an approach.

\section{IMPACT/APPLICATIONS}

The Seaglider/PAAM detection and recording system has achieved an initial operational capability with a single omnidirectional hydrophone. Additional omnidirectional hydrophones will add spatial diversity to combat signal shielding by the body of the Seaglider. The additional hydrophones will also constitute a limited acoustic array, with the ability to associate rough bearings with the detected vocalizations.

The Seaglider/PAAM system has the frequency range, computational power and flexibility, and persistence to be capable of a wide range of passive acoustic detection and recording missions. It is especially suitable for higher-frequency applications, where hydrophones can be small and large acoustic aperture is not required. It is capable, however, of recording vocalizations in the tens of $\mathrm{Hz}$ range, with somewhat decreased sensitivity.

Once the PAAM Rev. B boards are tested and installed in the Seaglider, a multi-month demonstration mission in one of the Navy operating areas would be possible.

In the fall of 2012, iRobot announced they were leaving the Seaglider business and closing their entire maritime division. This public announcement caused the UW to provide notification of termination of iRobot's license to the Seaglider technology. This termination was effective in November 2012. By mid-2013, the UW had awarded an exclusive license to Kongsberg Underwater Technology, Inc., of Lynnwood WA, to manufacture and sell Seagliders. As was true under the iRobot agreement, the UW retains the right to manufacture Seagliders for internal UW customers.

APL-UW would consider proposals to install the PAAM system into Seagliders purchased from Kongsberg Underwater Technologies, Inc. It may be possible to license the PAAM technology to Kongsberg so that they could factory-install the system.

The PAAM system can also function in other physical contexts: moorings, winched profilers, or cabled observatories, for example. Each application would require its own packaging, of course, but the system's origin as a Seaglider sensor means that it is, by definition, small, lightweight, and low-power. 
It is important to note that the Seaglider/PAAM system is treated as a U.S. export controlled item, both under the Department of State's ITAR and the Department of Commerce's EAR programs. We will only provide the PAAM system to verifiable U.S. persons, in situations where no export license is required. It will then be the responsibility of the purchasing investigator to remain in compliance with all applicable export control regulations.

Note that a list of publications follows the figures below.

\section{RELATED PROJECTS}

The primary related project was the previous ONR-funded PAAM work, under N00014-08-1-0309, as mentioned above. That project performed the initial PAAM development, and carried out four major sea trials, including short deployments at both AUTEC and SCORE. It ended on 30APR2011. There are many related projects to use passive acoustics on autonomous platforms to detect, classify, and monitor marine mammals; some are funded as part of ONR's broader PAAM program, some are supported elsewhere.

Dr. David Mellinger at OSU is directly funded by ONR under the PAAM program to provide beaked whale detection and classification algorithms. Dr. Mellinger and his colleague Dr. Holger Klinck also provide consultation on the placement and use of the multiple hydrophones on the Seaglider/PAAM system. They also carried out analysis of the 2012 Washington coast data. Those results are reported separately.

An important follow-on project is a subcontract award to APL-UW from Drs. Mellinger and Klinck at OSU, as part of their contract to provide passive acoustic marine mammal surveys and analysis in Navy operating areas to NAVFAC through their contractor HDR, Inc. Deployments of the Seaglider/PAAM system developed under this award will be made in the Marianas Islands, Hawai'i, and Gulf of Alaska operating areas. The recorded acoustic time series will be delivered to Drs. Mellinger and Klinck at OSU for analysis; results will be submitted to HDR, Inc., for transmittal to NAVFAC and COMPACFLT. 


\section{FIGURES}

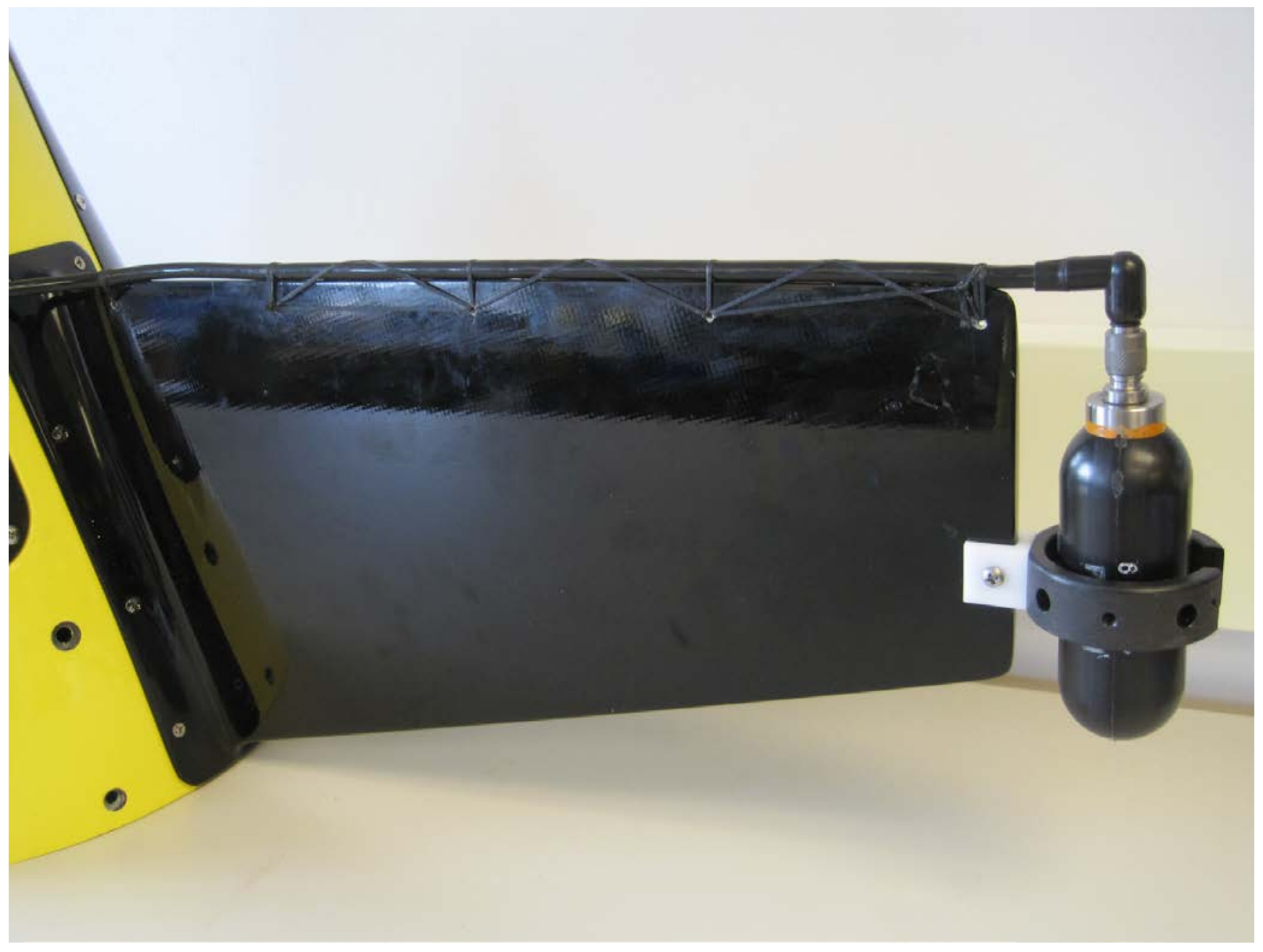

Figure 1. SeagliderS/N 178 aft fairing with port wing and wingtip-mounted HTI-99-HF hydrophone. Aft is up in this picture; the hydrophone cable is routed and lashed along the trailing edge of the wing, then through a hole in the dorsal Seaglider ${ }^{\mathrm{TM}}$ aft panel. An mirror-image installation was done on the starboard wing. The lashing was covered by black tape during the initial field trial. 


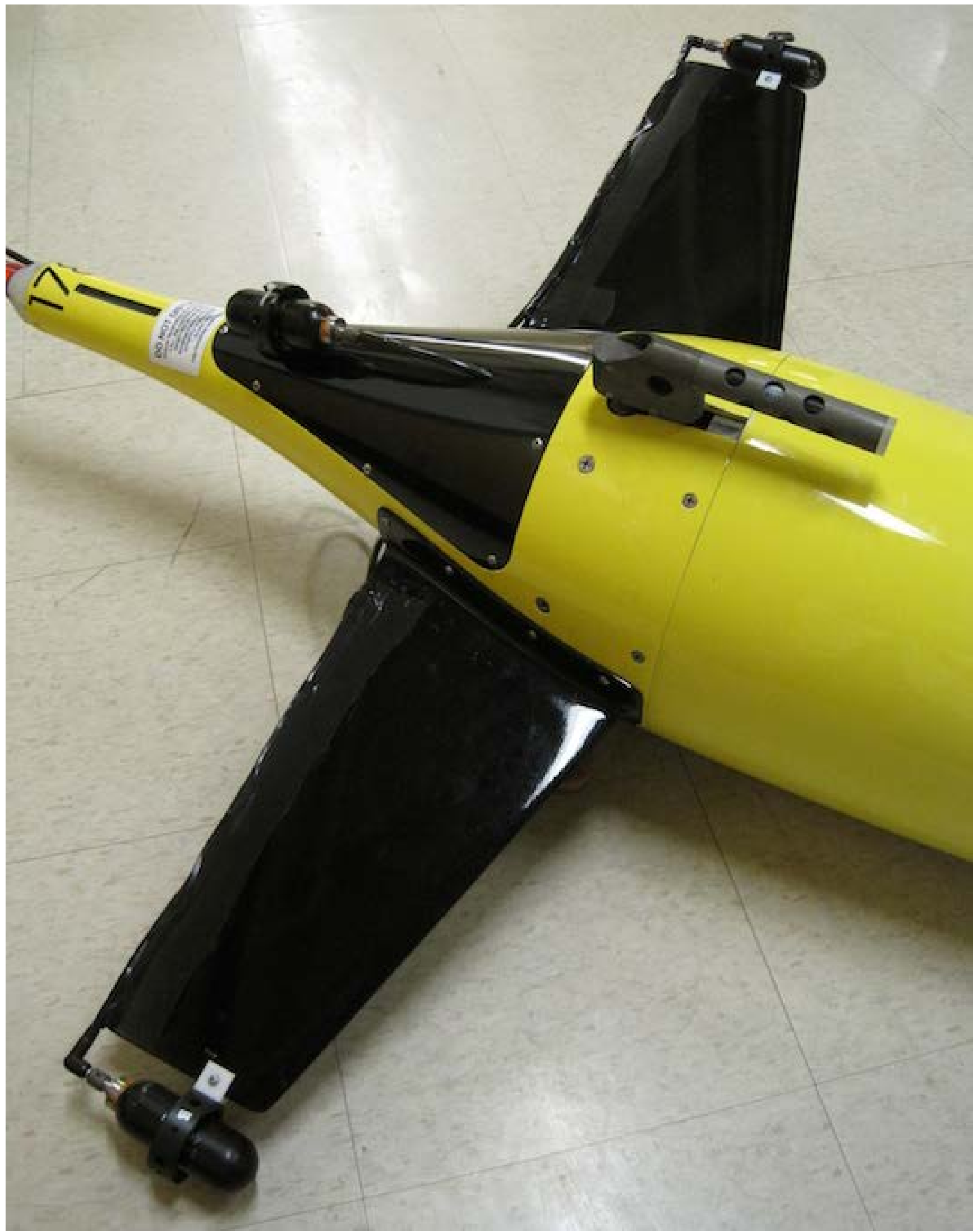

Figure 2. Seaglider ${ }^{\mathrm{TM}}$ S/N 178 with three HTI-99-HF hydrophones - one on each wingtip and one in the original position on the centerline. 


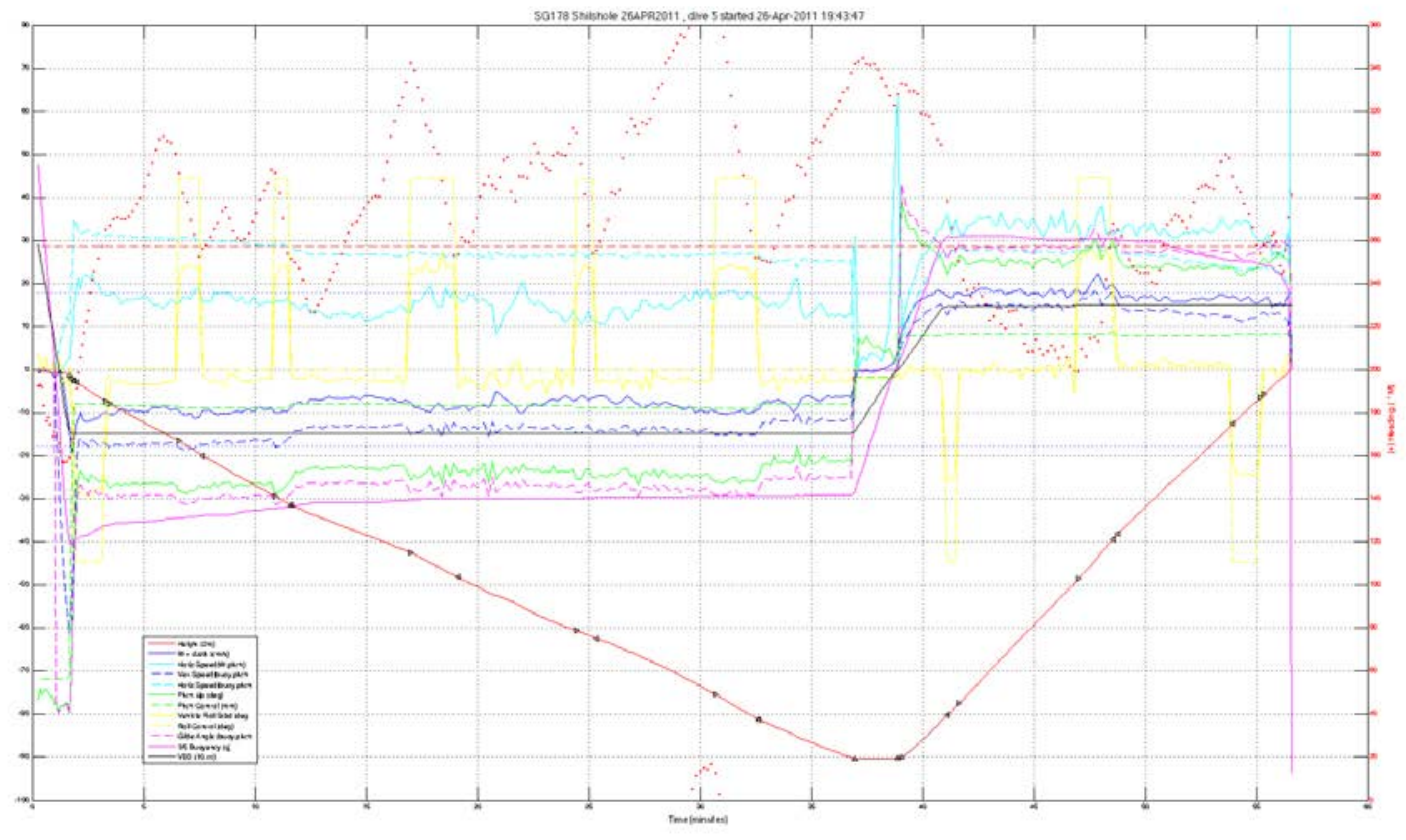

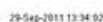

nomete

Figure 3. Plot of Seaglider ${ }^{\mathrm{TM}}$ S/N 178 dive 5 in Shilshole Bay, Puget Sound WA, on 26APR2011 with wingtip-mounted hydrophones. The horizontal axis is time, each tick mark is five minutes. The vertical axis carries various scales, but for the red curve, which is glider depth, each tick mark is 20 meters. Seaglider ${ }^{\mathrm{TM}} \mathrm{S} / \mathrm{N} 178$ was ballasted light for this mission, hence the slower descent and faster ascent. Other quantities plotted on this curve are all within normal limits for Seaglider ${ }^{\mathrm{TM}}$ operations. 


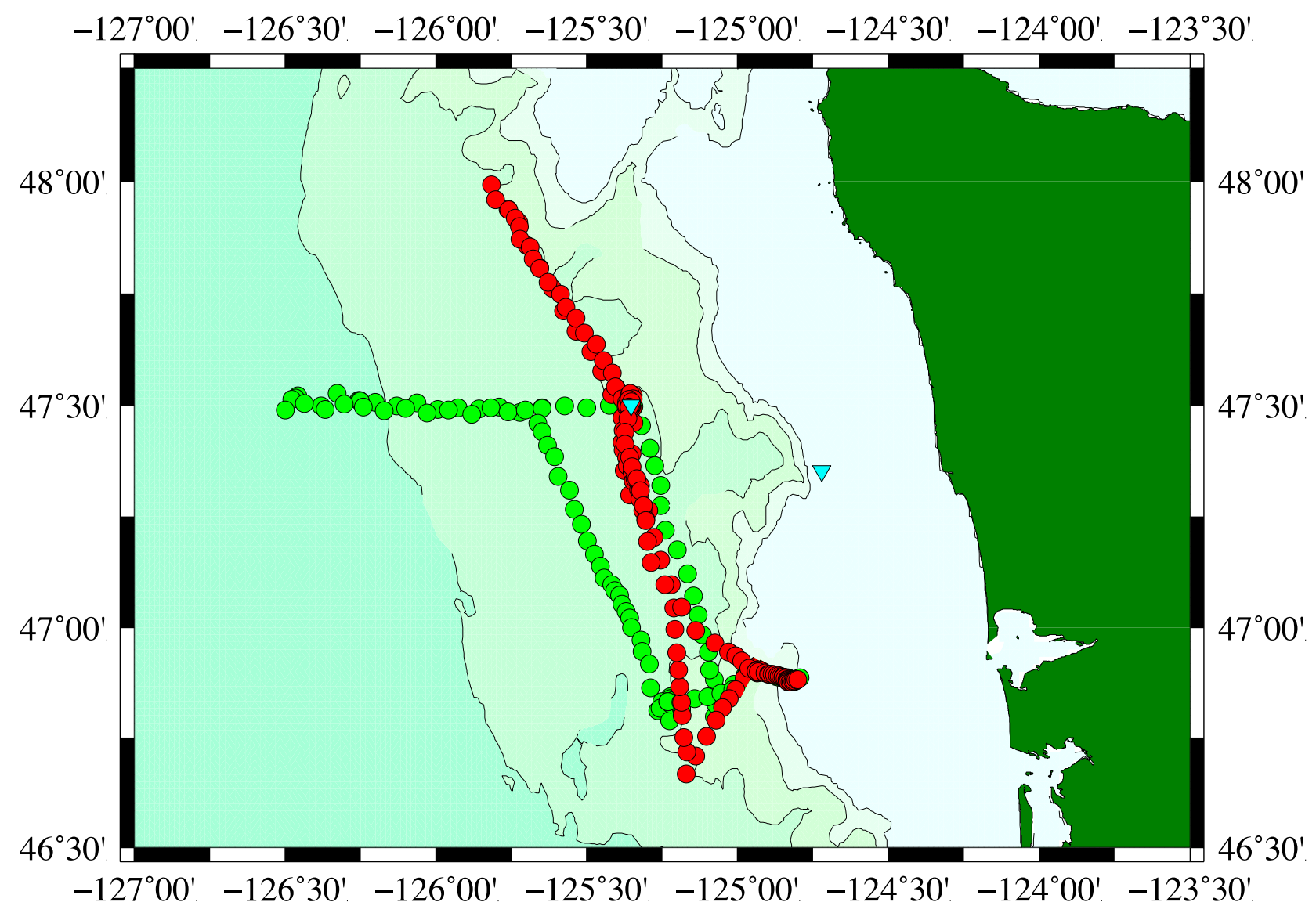

Figure 4. Surfacing positions of Seagliders S/N178 (green) and S/N179 (red) 11JUN-12JUL2012. HARP mooring locations (Wiggins, private communication) are indicated by inverted cyan triangles. The one-month mission demonstrated the Seagliders' ability to perform transects and to survey along designated isobaths.

\section{PUBLICATIONS}

Mellinger, David K., Holger Klinck, Neil M. Bogue, Jim Luby, Haru Matsumoto, and Roland Stelzer, Gliders, Floats, and Robot Sailboats: Autonomous Platforms for Marine Mammal Research, JASA 04/2012, 131(4), 3493.

Klinck, Holger, David K. Mellinger, Karolin Klinck, Neil M. Bogue, James C. Luby, William A. Jump, Geoffrey B. Shilling, Trinal Litchendorf, Angela S. Wood, Geogory S. Schorr, and Robin W. Baird, Near-real-time Acoustic Monitoring of Beaked Whales and Other Cetaceans Using a Seaglider ${ }^{T M}$, PLoS ONE 01/2012, 7(8).

Klinck, Holger, David K. Mellinger, Marie A. Roch, Karolin Klinck, Neil M. Bogue, Jim C. Luby, William A. Jump, John M. Pyle, Geoffrey B. Shilling, Trina Litchendorf, and Angela S. Wood, 
Passive-acoustic Monitoring of Odontocetes using a Seaglider: First Results of a Field Test in Hawai'ian Waters, JASA 01/2011, 129. 


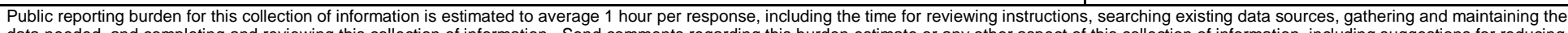

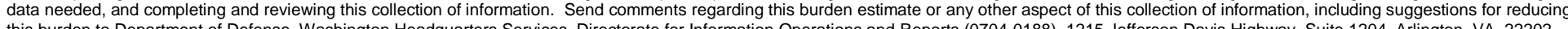

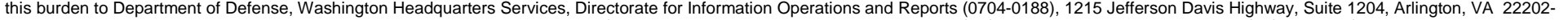

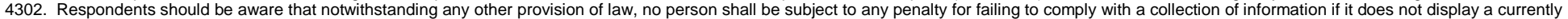
valid OMB control number. PLEASE DO NOT RETURN YOUR FORM TO THE ABOVE ADDRESS.

\begin{tabular}{l|l|l}
\hline 1. REPORT DATE (DD-MM-YYYY) & 2. REPORT TYPE & 3. DATES COVERED (FrOm - To)
\end{tabular}

\begin{tabular}{l|l}
$30-01-2015$ & Final Technical
\end{tabular}

4. TITLE AND SUBTITLE

Passive Acoustic Monitoring of Marine Mammals:

System Development Using Seaglider

April 2010 - December 2013

5a. CONTRACT NUMBER

5b. GRANT NUMBER

$\mathrm{N} \odot 0014-10-1-0515$

5c. PROGRAM ELEMENT NUMBER

6. AUTHOR(S)

Neil M. Bogue

5d. PROJECT NUMBER

5e. TASK NUMBER

5f. WORK UNIT NUMBER

8. PERFORMING ORGANIZATION REPORT NUMBER

7. PERFORMING ORGANIZATION NAME(S) AND ADDRESS(ES)

University of Washington - Applied Physics Laboratory

4333 Brooklyn Avenue NE

Seattle, WA 98105-6613

9. SPONSORING I MONITORING AGENCY NAME(S) AND ADDRESS(ES)

10. SPONSOR/MONITOR'S ACRONYM(S)

Office of Naval Research

ONR BDCC

One Liberty Center

875 North Randolph Street, Suite 1425

Arlington, VA 22203-1995

12. DISTRIBUTION I AVAILABILITY STATEMENT

Distribution Statement A: Approved for public release; distribution is unlimited.

\section{SUPPLEMENTARY NOTES}

\section{ABSTRACT}

This award was the second to APL-UW under ONR'S Passive Autonomous Acoustic Monitoring (PAAM) program. It was intended to further develop the Seaglider PAAM system in various ways: redesigned hardware to improve computational and data storage efficiency, multiple hydrophones for enhanced detection and localization, and, in collaboration with colleagues at Oregon State University, improved detection and localization algorithms. A new electronics board was designed and built, with additional CPLDs and a bank of eight microsD cards for data storage. Software upgrades were written to enable long-duration (multi-month) missions. Survey missions became a high priority, particularly in remote U.S. Navy operating areas. Paths were established so that the Seaglider/PAAM system could be made available to other researchers.

\section{SUBJECT TERMS}

16. SECURITY CLASSIFICATION OF: Unclassified

a. REPORT Unclassified b. ABSTRACT Unclassified c. THIS PAGE Unclassified
17. LIMITATION OF ABSTRACT

UU
18. NUMBER OF PAGES

13 19a. NAME OF RESPONSIBLE PERSON Laslie Harding 19b. TELEPHONE NUMBER (include area code) (206) 543-7048 